\title{
Universal Transcendental Logic-Based Ontology
}

\author{
Oleg V. Moroz ${ }^{1}$ \\ ${ }^{1}$ National Aviation University, Kyiv, Ukraine \\ Correspondence: Oleg V. Moroz, Software Engineering Department, National Aviation University, 1, \\ Liubomyra Huzara ave. Kyiv, Ukraine 03058.
}

Received: January 6, 2021

Accepted: January 28, 2021

Online Published: February 8, 2021

doi:10.5539/cis.v14n2p1

URL: https://doi.org/10.5539/cis.v14n2p1

\begin{abstract}
In this paper, Kant's philosophical doctrine of the categories of the reason is used to substantiate the conceptual model of knowledge representation, based on the collective interaction of a lot of intellectual atomic elements of knowledge (knowledge quanta), which are combined into clusters like neurons in the brain; and also a phenomenological description of the corresponding universal ontology, proceeding from the philosophical premise of Husserl-Heidegger that the meaning of intelligence is not so much in knowing the absolute truth as in survival, is presented. In the process of cognizing the surrounding world, a person uses both a priori knowledge and a posteriori knowledge, but the transcendental content of a priori forms of thinking does not allow them to be used directly in logical judgments. Nevertheless, one can try to use them as "ontological predicates" following the advice of I. Kant, what was done in this article. Heuristic ontological relations that directly follow from the categories of Kant are easy to use and sufficient to describe any ontology. Offered knowledge representation model, the key idea of which is the primacy of knowledge to logical inference and their emergent ability to self-organize, in conjunction with the transcendental logic-based ontology of empirical knowledge can be used to create a universal inference engine.
\end{abstract}

Keywords: knowledge representation, knowledge self-organizing, transcendental logic, ontology

\section{Introduction}

The stumbling block for creating artificial intelligence is the question of the origin of knowledge - cognition. The origins of modern epistemology were laid by I. Kant's categories of reason. According to I. Kant, both the forms of thinking and the forms of perception can be a priori (pure) and empirical. He defined the a priori categories of reason, on which depends how we see and understand the world, and which are a priori abstract forms of thinking. To apply them to reality, that is, to go over to a posteriori forms of thinking, they must be superimposed on a priori forms of perception, which are time and space. It should be borne in mind that one cannot limit the cognition of the surrounding world by the conscious phenomenological perception in space and in time, forgetting about the possibility of the subconscious (heuristic) cognition through communication with the Creator. It is the presence of such a connection that distinguishes the human being as a special type of organic life on Earth from animals; without this connection, his full intellectual development is impossible.

Explaining the essence of his doctrine of the categories of reason in the "Critique of Pure Reason", Kant says that "the categories themselves are not knowledge at all, but only forms of thinking to generate knowledge from these contemplations" (Kant, 1922). In other words, new knowledge is obtained because of superimposing rational categories (a priori forms of thinking) on perceived reality in the process of observation. The list of Kant's thinking categories is necessary and sufficient to ensure experience and cognition, ensuring the acquisition of new knowledge not only through perception using a priori forms of thinking but also through a posteriori forms of thinking (judgments) and already existing knowledge, that is, by analyzing acquired experience when judgments are applied to already existing knowledge.

Kant also put forward the idea that there must be another, different from the formal (Aristotelian) logic, the subject of which should be the categories of reason. He called this science "the science of pure reason" or transcendental logic. Formal (general) logic formulates rules relating to all entities (a priori and empirical), its rules are valid for pure a priori knowledge, but they do not consider the specifics of this knowledge which is that it cannot be directly an object of empirical forms of thinking, though it is contained in empirical knowledge and can be revealed through reasoning. Transcendental logic deals with "transcendental content", it "does not show 
us what properties an object has, but indicates how we should, guided by it, reveal the properties and connections of objects of experience in general"(Kant, 1922). Thus, transcendental logic concerning general logic has a "regulatory application", which Kant himself called a heuristic.

The idea of Kant's transcendental logic arose from the inadequacy of the apparatus of formal logic for solving the problems of metaphysics and the theory of knowledge, but he deduced the categories of reason from the theory of judgments, that is, from general logic, therefore there are as many categories of reason as there are types of judgments in general logic. It is not surprising that modern artificial intelligence systems based on modeling formal-logical inferences are limited in their capabilities for modeling the cognitive process. As noted in (Moroz, 2020), their limitations are due to the following reasons:

1. Knowledge is not decisive for intelligence, although, as commonsense reasoning suggests, intelligence is, first, knowledge, no knowledge - no intelligence. "Stupid as a child" - that is saying about a person who lacks knowledge. The focus is made on logical inference, which is built on formal logic with all its shortcomings.

2. Knowledge is separate from thinking and is not active. In the architecture of these systems, two main components are distinguished: the inference engine and the knowledge base. At the same time, regardless of the knowledge representation model (decision trees, semantic nets, predicate calculus, and so on), the knowledge base is very limited, so that with its growth, its inconsistency also grows, that leads to the need to use another component in the system - the explanatory interface. This division is a direct consequence of the rather widespread misconception that the brain is a computer and thinking is a program. That is not right since knowledge is an active substance, the forms of activity of which are inextricably linked with the process of thinking and, thus, with consciousness.

All the above applies equally to other models of intelligence, such as neural, genetic, or social, which are trying to overcome the rationalistic legacy of previous generations of artificial intelligence (Luger, 2009). They produce inferences not based on logical rules but based on a collective decision generated by a sufficiently large number of interacting agents. All of them are artificial narrow intelligence and follow pre-programmed rules in their functioning, so their decisions seem to be reasonable, especially in cases of "deep learning" where the system can learn and adapt really. A prime example of this is the use of Artificial Neural Networks to simulate symbolic computation, presented in the paper (Lample \& Charton, 2019), where a neural network was used that "remembers the context", that is, it considers the meaning of words depending on which words are near to them. Meanwhile, the fact that the meaning of any utterance depends on the context of its use was argued by $\mathrm{L}$. Wittgenstein (Wittgenstein \& Anscombe, 1953), who revised the concept of meaning in natural and formal languages. Like M. Heidegger (Heidegger; Macquarrie, \& Robinson, 1962), Wittgenstein has repeatedly criticized the rationalist traditions in modern philosophy and science in his studies.

Despite the rejection of logical conclusions like the main mechanism of thinking, the achievements of such models of artificial intelligence, although advertised quite widely and ambitiously, are very modest in terms of artificial general intelligence, and sometimes their intellectual abilities lead to curiosities. They lack flexibility and ability to learn (cognition), in a universal human broad sense, and their application is limited by the framework of private ontologies.

In this paper which is the continuation of the paper (Moroz, 2020), Kant's philosophical doctrine of the categories of the reason is used to substantiate the conceptual model of knowledge representation, based on the collective interaction of a lot of intellectual atomic elements of knowledge (knowledge quanta), which are combined into clusters like neurons in the brain, and also a phenomenological description of the corresponding universal ontology, proceeding from the philosophical premise of Husserl-Heidegger that the meaning of intelligence is not so much in knowing the absolute truth as in survival, in knowing its place in this world, is presented.

\section{Method}

Understanding the relationship between general and transcendental logic is very important since both are rules for gaining new knowledge, deriving some concepts from others. The difference between them lies in the attitude to the content of knowledge: general logic is abstracted from any content of the concepts with which it operates, and transcendental logic deals with a certain content - "transcendental content". Because of the limitations of general logic, there is a natural desire to apply transcendental logic to model the universal mechanism of logical inference in artificial intelligence systems. However, here we are faced with a problem essentially since transcendental logic as an integral part of the mind is not directly applicable to a posterior knowledge. The role of transcendental logic "consists in limiting the set of all possible conclusions of the given judgments. Not all 
conclusions deemed valid by formal logic are valid from the perspective of transcendental logic; and what is more important, the limitations to space, within which the search for logical inference is conducted, are not arbitrary, but have clear ontological bases relating to Kant's limitations on the application of categories» (Bryushinkin, 2011).

Moreover, transcendental logic cannot be formalized, since it is inherently heuristic, although some researchers make attempts to construct a certain logical formalization corresponding to the Kantian categories of reason, based on geometric logic (Achourioti \& van Lambalgen, 2011) and input/output logic (Evans, Sergot, \& Stephenson, 2020), that is it is about the construction of intuitionistic semantics of transcendental logic. An alternative way of developing symbolic computation based on transcendental logic can be the introduction of ontological relations between concepts, especially because I. Kant wrote in one of his letters concerning the categories that "their logical employment consists in their use as predicates of objects" and called them "ontological predicates" (Kant, 1914). In (Bryushinkin, 2011), these relations are based on P. Strawson's descriptive metaphysics. In this paper, we have defined twelve kinds of relations, which heuristically resulting from the original Kant's categories.

As well as thinking, which is categorical, knowledge being a product of thinking is also categorical, that is, it consists of the concepts referring to certain categories (types, classes) and having the relationships that do not contradict the a priori forms of cognition and thinking and allow to evaluate the meaning of these concepts depending on the context used. So, we consider the structural atomic elements of knowledge such as referring to different categories connected by the ontological relations. Table 1 presents these relations and the corresponding initial Kant's categories.

Table 1. Ontological relations and the corresponding initial Kant's categories

\begin{tabular}{ll}
\hline \multicolumn{1}{c}{ Ontological relations } & \multicolumn{1}{c}{ Initial Kant's categories } \\
\hline Relation of subordination & Reality, Negation \\
Relation of generality & Unity, Plurality \\
Relation of aggregation & Plurality, Totality \\
Relation of modality & Possibility/Impossibility, Existence/Non-existence, \\
& Necessity/Contingency, \\
Relation of order & Inherence and Subsistence \\
Relation of causality & Unity, Plurality \\
Relation of tactility & Causality and Dependence \\
Relation of vitality & Community, Inherence, and Subsistence \\
Relation of wisdom & The reason as such (the super-category) \\
& Inherence and Subsistence, Causality and \\
Relation of chaos & Dependence \\
Relation of variability & Unity, Negation \\
Relation of effectiveness & Community, Negation \\
\hline
\end{tabular}

The first six relations express the meaning of the philosophical concepts of quantity and quality, cause and effect, and modality. They do not require additional explanation and are used to describe phenomena much more often than others. The same can be said for the attitude "Relation of variability" which describes the ability to change the concept itself that is its state or properties, for example, "flexible concept", "blue sky", "hard stone", "bird flies", "car rides" and so on.

"Relation of tactility" allows setting a degree of semantic proximity between different concepts, for example, "winding coast" (like a curve), "head engineer" (like a head), "wonderful evening" (like any surprise phenomenon).

As for "Relation of vitality", all the Kant's categories are the subcategories of the super-category of the reason as such, that is the reason as an implementation of the creation, that which exists, but is not given to us in 
perceptions, neither pure nor empirical. "Relation of vitality" defining the role in the life of the individual corresponds to this super-category. This attitude is always associated with the answer to the question "What is the most important thing in life?" or "What is the meaning of life?". The answer is always subjective and original in each specific implementation.

"Relation of wisdom" sets influence on mental abilities in a broad sense like stupid-trick, logical-illogical, reasonable-stupid, and so on, for example, "smart horse", "illogical actions".

"Relation of chaos" corresponds to the randomness of the established relationship. For example, «red elephant» - this is not realistic but maybe in imagination.

"Relation of effectiveness" sets the ability to generate control instructions, the desire to be first, to make others dependent on yourself and others, for example, "soldier goes to the attack" (command "attack"), "stand in line" (command "stand").

Consider the following example: "Heating water causes it to evaporate." In this case, steam is a consequence of water heating, that is, the concept of "steam" is related through the "Relation of causality" to the concepts of "heating" and "water", but not to these concepts themselves, but to the connection between them, which refers to "Relation of variability". So, "Relation of causality" characterizes the causal nature just of the relationship between the concepts of "heating" and "water".

Consider another example: "The car is driving on the road." Here the concepts of "car" and "drive" are linked by the "Relation of variability" (this state of the machine is "driving"), and the concept of "road" additionally characterizes, but not the concepts of "car" or "drives", but their relation, that is the concept of "road" is related to the relationship between the concepts of "car" and "drives" using the same "Relation of variability".

And one more example: "Twilight, fog, sad ...". Here are no relationships between the concepts at all - they are linked by meaning, by context.

The ontological relations presented in Table 1 are easy to use and sufficient to describe any ontology. In this case, one should keep in mind a few simple rules for using them:

1. The ontological relations can express both connections between two concepts and between concept and relation. In the first case, the relation characterizes both concepts associated with it, in the second - the concept acts as an additional characteristic of the relationship associated with it.

2. One can use concepts between which there is no ontological connection, but they can be related by the context of use, they can be united by the context in meaning. The meaning of any statement (not necessarily verbal) is determined by the mind. When we say, "this is meaningless," it means that something goes beyond the reasonable, contradicts the transcendental content of our thinking. In any situation, we check our common sense, not realizing that this is just our mind, but it depends on the situation and on that who makes the decision.

3. Relations can be nested, and the depth of nesting is limited only by common sense.

4. And, finally, when applying these relations to construct an ontology, one should not forget that the starting point for them is not the establishment of ultimate truth, but the description of knowledge gained from experience, usually by trial and error.

Figure 1 shows the ontological diagram for the chain of thinking corresponding to the utterance "The mountain was very high and overgrown with forest". Recall that chain of thinking, as the result of the process of thinking, consists of copies of interrelated knowledge quanta with the same polarization, which can be in any of the nodes of the knowledge tree. In this chain of thinking, the key quantum (concept) is the "mountain"; it contains information about all quanta included in the chain in the form of a list. Each of these quanta has its own set of polarization frequencies, determined by the relationship between their respective concepts, and - the rating value depending on the importance of the linked concept for the utterance as a whole. In the chain of thinking under consideration, "was" has the highest rating, "high" and "overgrown" have lower rating and their ratings are equal, and "very" and "forest" also have the same rating and it is the smallest rating.

The meaning of the whole statement is determined by analyzing the ontological relations between the concepts included in it and their ratings in terms of the value of this statement for the cognitive process. Everyone has his life values, therefore the meaning of the same statement for different people may differ and even change depending on the situation for the same person. 


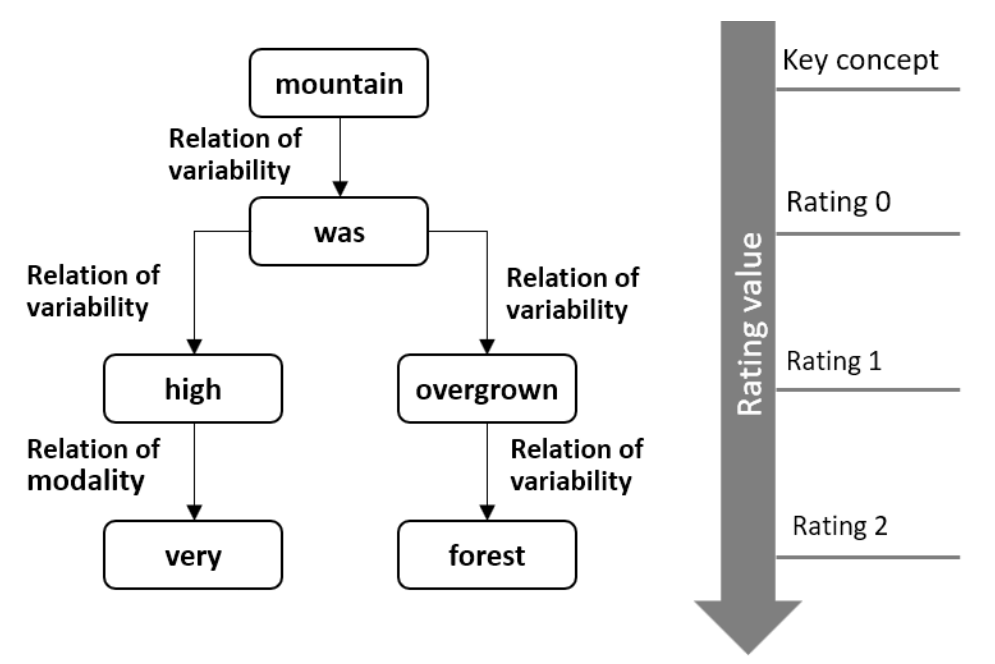

Figure 1. Ontological diagram of the utterance "The mountain was very high and overgrown with forest"

\section{Results}

There are a great many entities in the world surrounded us, each of which has a certain set of properties and characteristics that manifest through interaction with other entities. Knowledge about this world, regardless of its origin, generates new knowledge. This is a permanent process, and there are no restrictions on the formation of knowledge structures, except for those that are determined both by a priori forms of thinking and perception and by the nature of the knowledge itself and its emergent ability to self-organize. The mind controls the perception of the surrounding world through the cognitive system and determines the reaction of the organism in each specific situation, but this requires a suitable ontology in which all the acquired empirical knowledge would be stored. A descriptive model of such an ontology in the form of a hierarchical categorical structure called the knowledge tree was proposed in (Moroz, 2020). The nodes of this knowledge tree are containers in which clusters of knowledge (concepts) are accumulated, consisting of quanta of knowledge connected by ontological relations from Table. 1. There is also a detailed description of the procedure for adding a quantum of knowledge to a cluster, controlled by some intelligent device, which results in creating new knowledge and the syntax of which can be considered as a procedural implementation of the process of thinking.

In the paper (Moroz, 2020), only some of the nodes of the knowledge tree were considered in the context of describing the conceptual model of knowledge representation. Below there is a complete description of the nodes of the first three main levels of the knowledge tree that make up its framework. Leaf nodes of the fourth level are not so essential, except for the subtree with the root node "Life of a biological creature", related to Behavioral knowledge, which is of key importance for knowledge organizing. There are a lot of them, and their composition may vary, therefore they are not presented here. Those categories of knowledge that are debatable and may cause questions are provided with appropriate comments.

1. Behavioral knowledge (behavior in the surrounding world)

\subsection{Treatment and disease.}

1.1.1. Symptoms.

1.1.2. Causes of diseases.

1.1.3. Soul healing.

1.1.4. Physical body treatment.

1.1.5. Mind healing.

1.2. The technique of pattern recognition.

1.2.1. Support elements recognition.

1.2.2. Establishing support elements that are unchanged with respect to image transformations.

1.2.3. Establishing an image frame from immutable support elements.

1.2.4. Rotational symmetry.

1.2.5. Plane symmetry. 


\subsection{Social behavior.}

1.3.1. Social development laws.

1.3.2. Social order laws.

1.3.3. Laws of social collapse.

1.3.4. Desocialization (deactivation of social principles).

1.3.5. Model of effective social life.

1.4. Behavior in extreme situations.

1.4.1. Analysis of the current situation.

1.4.2. Analysis of the possible development of the situation.

1.4.3. Analysis of the actions taken.

1.4.4. Analysis of possible actions.

1.4.5. Analysis of the consequences of possible actions.

1.5. Life of a biological creature.

1.5.1. Attracting life potential (survival).

1.5.1.1. Search engine and pattern recognition.

1.5.1.2. Decision-making methodology.

1.5.1.3. Adaptation to a changing environment.

1.5.1.4. Biological evolution.

1.5.1.5. Spiritual enhancement.

1.5.2. Perceptual memory.

1.5.2.1. Visual memory.

1.5.2.2. Auditory image memory.

1.5.2.3. Memory of tactile images.

1.5.2.4. Memory of olfactory images.

1.5.2.5. Memory of nerve endings (shock, fracture, etc.).

1.5.3. Motor memory.

1.5.3.1. Memory for simple movements.

1.5.3.2. Memory for static body positions (postures).

1.5.3.3. Memory for complex movements (combinations of simple movements).

1.5.3.4. Memory for congenital movements.

1.5.3.5. Memory for movements causing trauma.

1.5.4. Reproductive function.

1.5.4.1. Puberty in adolescents.

1.5.4.2. Turning on the genital function at full power.

1.5.4.3. Operation of the laws of copulation (the process of conception).

1.5.4.4. Operation of the laws of motherhood.

1.5.4.5. Extinction genitals functions.

1.5.5. Communication with the Creator.

1.5.5.1. Subconscious (intuition).

1.5.5.2. Soul (grain of the Creator).

1.5.5.3. Prayer.

1.5.5.4. Daily transmission of information through the channel of communication with the Creator.

1.5.5.5. The brain as being (a priori forms of perception and thinking).

2. Verbal knowledge (communication with other people)

\subsection{Connections between people.}

2.1.1. Connections during casual communication.

2.1.2. Relationships during love games.

2.1.3. Connections during the fight against enemies.

2.1.4. Connections during work.

2.1.5. Connections while caring for others.

2.2. Connections in a situation of danger.

2.2.1. Connections with people who perceive the situation.

2.2.2. Connections with people who can make a difference.

2.2.3. Connections with people who can help.

2.2.4. Connections with people who can advise on how to get out of danger.

2.2.5. Connections with people who can blow up a situation. 


\subsection{Connections with people who seem inadequate.}

2.3.1. Connections with sick people.

2.3.2. Connections with people who feign illness.

2.3.3. Connecting with people who do bad things.

2.3.4. Connections with people who treat sick people.

2.3.5. Connections with people with symptoms of the disease.

2.4. Communication with people who commit non-standard (unpredictable) acts.

2.4.1. Connections with people who are losing their temper.

2.4.2. Connections with people who cannot control themselves.

2.4.3. Connections with people who do not understand what is going on.

2.4.4. Connections with people who live only for themselves and do not respect others.

2.4.5. Connections with people who understand what is going on but do not know what to do.

2.5. Connections with people who crave power.

2.5.1. Connections with people who go to great lengths for power.

2.5.2. Connections with people who have power, but that is not enough for them.

2.5.3. Connections with people who can be hypocrites.

2.5.4. Connections with people who have lost conscience for the sake of power.

2.5.5. Connections with people who are willing to give up their last things for power.

3. Search engine (information search)

\subsection{Finding information about life.}

3.1.1. Finding information about the life of living beings.

3.1.2. Finding information about the insentient substance.

3.1.3. Finding information about living forms.

3.1.4. Finding information about insentient substance forms.

3.1.5. Finding information about the state of life on the planet.

3.2. Finding information about people.

3.2.1. Finding information about people in general.

3.2.2. Finding information about people who are involved in survival issues on a global scale.

3.2.3. Finding information about people who are involved in wildlife survival.

3.2.4. Finding information about people who are involved in survival in extreme situations.

3.2.5. Finding information about people who are involved in survival in normal conditions.

3.3. Finding information in global knowledge bases.

3.3.1. Finding information about scientific achievements.

3.3.2. Finding information about social and political life.

3.3.3. Finding information about entertainment and leisure.

3.3.4. Finding health information.

3.3.5. Finding information about work and work activities.

3.4. Find training information.

3.4.1. Finding information for general knowledge.

3.4.2. Finding information for vocational training.

3.4.3. Finding information about relationships between people.

3.4.4. Finding information to establish the exact reasons for what is happening.

3.4.5. Finding information on what to do in the current situation (for deciding).

3.5. Finding information about happy events.

3.5.1. Finding information about events that can bring joy.

3.5.2. Finding information about events and phenomena that can bring success in life.

3.5.3. Finding information about events that can infuriate.

3.5.4. Finding information about events that may give a desire to improve.

3.5.5. Finding information about the events that can give a desire to smile (to give joy.)

4. Knowledge about the structure of the external environment and its place in it (how the world works)

4.1. Consciousness.

4.1.1. Perception.

4.1.2. Thinking.

4.1.3. Memory tree (events in the life of an individual).

4.1.4. Feelings.

4.1.5. Emotions. 


\subsection{Microcosm}

4.2.1. The atom and its structure.

4.2.2. Elementary particles.

4.2.3. Knowledge concerning the foundations of the universe (future discoveries).

4.2.4. Knowledge concerning the foundations of the universe (future discoveries).

4.2.5. Knowledge concerning the foundations of the universe (future discoveries).

\subsection{Macrocosm}

\subsubsection{Earth.}

4.3.2. Solar system.

4.3.3. Galaxy.

4.3.4. Universe.

4.3.5. Singularity (expansion of the universe to such extent that it can be perceived by the mind).

4.4. Organic life.

4.4.1. Organic molecules.

4.4.2. Clumps of organic molecules.

4.4.3. Protozoa (microbes).

4.4.4. Arable, coelenterates, and plants.

4.4.5. Mammals and humans as the special kind of organic life on the Earth.

4.5. The states of matter.

4.5.1. Solid.

4.5.2. Liquid.

4.5.3. Gaseous.

4.5.4. Plasma.

4.5.5. Energy vibrations (vibrations of the energy bodies of the human and his soul).

5. Knowledge of work activity (how to do something)

\subsection{Professional work.}

5.1.1. Work that can bring joy.

5.1.2. Work that does not bring joy.

5.1.3. Work that gives new knowledge.

5.1.4. Work that poses problems in life.

5.1.5. Work that brings happiness.

5.2. Activities to create life benefits.

5.2.1. Wealth creation activities.

5.2.2. Activities to create funds for work.

5.2.3. Job creation activities.

5.2.4. Activities to create life tasks (goals).

5.2.5. Smart business activities.

5.3. Activities to create mechanisms that accelerate work.

5.3.1. Activities to create vital structures.

5.3.2. Activities to create vital work tools.

5.3.3. Activities to create lightweight work tools.

5.3.4. Activities for the creation of giant industrial complexes.

5.3.5. Activities to create mechanisms to accelerate the management process.

5.4. Creating places where economic policy is done.

5.4.1. Creating organizations for economic decision making.

5.4.2. Creating organizations to regulate economic processes.

5.4.3. Creating organizations that manage the tasks of making the laws of economic development.

5.4.4. Creating organizations that are engaged in the restructuring of the economic structure.

5.4.5. Creating organizations that treat economic communities.

5.5. Activity in creating organizations - economic pioneers.

5.5.1. Creating organizations that use new technologies.

5.5.2. Creating organizations that use new methods of work.

5.5.3. Creating organizations that use new devices.

5.5.4. Creating organizations that use new energy facilities.

5.5.5. Creating organizations that use new laws of economic development. 


\section{Discussion}

The proposed descriptive ontology of empirical knowledge does not claim to be complete, being only the result of the author's phenomenological research, however, one circumstance is beyond doubt - intellect was given to human being by the Creator to cognize the laws of its existence through interaction with the physical world, as well as to realize its place in this world, and, most importantly, to cognize Your Spiritual Self. While cognizing the surrounding world, a person uses both a priori knowledge and a posteriori knowledge, but the transcendental content of a priori forms of thinking does not allow them to be used directly in logical judgments. Nevertheless, one can try to use them as "ontological predicates" following the advice of I. Kant, what was done in this article. A priori categories of reason cannot be formalized, but their regulatory function for logical judgments can be realized in the form of ontological relations between concepts, from which semantic analysis can be built. This paper completes the description of the knowledge representation model presented in (Moroz, 2020), the key idea of which is the primacy of knowledge concerning logical inference and their emergent ability to self-organize. The offered knowledge representation model in conjunction with the transcendental logic-based ontology of empirical knowledge can be used to create a universal inference engine. The next stage of this research is the software implementation of this model.

\section{References}

Achourioti, T., \& van Lambalgen, M. (2011). A formalization of Kant's transcendental logic. Review of Symbolic Logic, 4(2), 254-289. https://doi.org/10.1017/S1755020310000341

Bryushinkin, V. N. (2011). Kant's Logic and Strawson's Metaphysics. Kantovsky Sbornik, 3(37), 7-17. Retrieved from https://journals.kantiana.ru/upload/iblock/ef6/ Bryushinkin\%20V.\%20N._6-15.pdf

Evans, R., Sergot, M., \& Stephenson, A. (2020). Formalizing Kant's Rules. J Philos Logic 49, 613-680. https://doi.org/10.1007/s10992-019-09531-x

Heidegger, M., Macquarrie, J., \& Robinson, E. S. (1962). Being and time. New York, NY: Harper.

Kant, I. (1781/1922). Critique of Pure Reason, 2nd ed. revised (F. Max Müller, Trans.) New York, NY: The Macmillan Company.

Kant, I. (1790/1914). Critique of Judgement, 2nd ed. revised (J.H. Bernard, Trans). London, England: Macmillan. Retrieved from https://oll.libertyfund.org/title/bernard-the-critique-of-judgement

Lample, G., \& Charton, F. (2019). Deep Learning for Symbolic Mathematics. Retrieved from https://arxiv.org/pdf/1912.01412.pdf

Luger, G. F. (2009). Artificial intelligence: Structures and strategies for complex problem solving (6th ed.). Boston, MA: Pearson Education, Inc.

Moroz, O. V. (2020). Model of Self-organizing Knowledge Representation and Organizational Knowledge Transformation. American Journal of Artificial Intelligence, 4(1), 1-19. https://doi.org/10.11648/j.ajai.20200401.11

Wittgenstein, L., \& Anscombe, G. E. M. (1953). Philosophical investigations. New York, NY: Macmillan.

\section{Copyrights}

Copyright for this article is retained by the author(s), with first publication rights granted to the journal.

This is an open-access article distributed under the terms and conditions of the Creative Commons Attribution license (http://creativecommons.org/licenses/by/4.0/). 